\title{
Social awareness as a support tool for analog TV switch off and humanization process: Seja Digital's experience in Rio Verde and Brasília (Brazil)
}

\author{
Deisy Fernanda Feitosa
}




\title{
Social awareness as a support tool for analog TV switch off and humanization process: Seja Digital's experience in Rio Verde and Brasília (Brazil)
}

\author{
FEITOSA, Deisy Fernanda, Consultant at Seja Digital ${ }^{1}$
}

\begin{abstract}
In order to attend regulatory order, Brazil's analog TV signal is in the process of switching off. The expectation is to switch off the analog signal of all major and medium-sized cities in Brazil until 2018. If everything goes according to plan, the digitalization of the entire country will complete by 2023. To ensure this, Seja Digital - EAD (entity responsible for the operation and analog signal switch off) has undertaken many actions guided by social mobilization. This article presents the blueprints of a project based on this methodology applied in Rio Verde city (Goiás State) and tested on other cities. It aims to support the population throughout the transition process by answering questions and scheduling the distribution of converter kits to families that receive social aid from federal government programs. Additionally, it presents a conceptual reflection on the meaning of social mobilization and justification for why it is so highly valued for TV switch off projects.
\end{abstract}

Index Terms - Brazilian Switch off; Digital TV; Analog TV; Seja Digital.

\section{INTRODUCTION}

To mobilize means to invoke the desire to partake in the search of a common purpose, under a shared interpretation and meaning. (TORO; WERNECK, 1996, p.5)

$\mathrm{B}^{y}$ y regulatory order, Brazil's analog TV signal is in the process of being switched off. The project's kickoff city was Rio Verde, in the Brazilian state of Goiás, on March 1 of last year. The second cluster $^{2}$ to have completed the digitalization process was in Brasília, on November 18. "Cluster" refers to the conglomerate of cities that will undergo the process according to the Brazilian analog switch off timeline. In this case, it refers to the Federal District plus its nine surrounding cities (Cristalina, Luziânia, Águas Lindas, Novo Gama, Valparaíso de Goiás, Formosa, Santo Antônio do
Descoberto, Cidade Ocidental, and Planaltina de Goiás). The expectation is switching off the analog signal of all major and medium-sized cities in Brazil by 2018. If everything goes according to plan, the digitalization of the entire country will reach completion by 2023. To ensure this, Seja Digital - EAD (entity responsible for the operation and analog signal switch off) has undertaken many courses of action, some of which are guided by social awareness.

Seja Digital's social mobilization project is sensitive to the population's awareness about the analog signal switch off and driven towards taking over this process and developing tools and mobilization solutions within its community. What we have done is established dialogue so that our participation may be as effective as possible and generate commitment, love, involvement, and a sense of community. All this adds value to the process, which in turn, no longer seen as merely technological change, also adds a sense of wellbeing and an awareness of the benefits offered by digital TV and technology. More and more it awakens a desire for digital inclusion. It has become a project of public use and we can only complete it through a chain of solidarity and collective effort, even more so because of a single truth we hold on to and have confirmed through our field experiences: the Brazilian people love television very much.

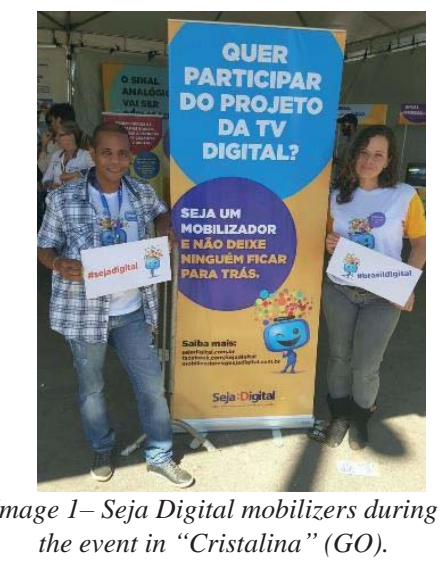


We have noticed that these actors feel valued and important to the process and in turn collaborate with us more freely and are more emotionally willing when we make them aware of the importance that television still holds to many families. We argue, and admit, that we cannot reach our goal alone. We need everyone's help and multipliers and volunteers are essential to guarantee that these families have access to digital TV signal.

This article presents the blueprints of a project based on this methodology applied in Rio Verde and tested on other clusters. It aims to support the population throughout the transition by answering questions and scheduling the distribution of converter kits to families that receive social aid from federal government programs. Additionally, it presents a conceptual reflection on the meaning of social mobilization and justification for why it is so highly valued for TV switch off projects.

This document is the first linked to the Brazilian Digital TV and Technological Convergence Observatory (Obted), a LabArteMídia research group project. Almir Almas, from the Cinema, Radio and Television Department at the School of Art and Communications of the University of São Paulo, is the coordinator at LabArteMídia (Laboratory of Art, Media and Digital Technology) ${ }^{1}$. The creation of Obted had the purpose of following the Digital TV implementation scenario in Brazil closely, while simultaneously making observations of television in the digital production era, reflecting on social changes and implications brought on by the digital system to this vehicle, which is currently going through a technological integration phase beyond broadcasting. Note that the Observatory is not limited to analyzing digital TV or the processes related to it with a critical eye. Instead, it has a collaborative nature to also offer solutions and increase knowledge. In other words, the project proposes to observe technological enhancements while identifying new possibilities for entertainment and discourse.

\section{SEJA DIGITAL: COMMUNICATION, MOBILIZING, AND MULTIPLYING IN ORDER TO DIGITALIZE}

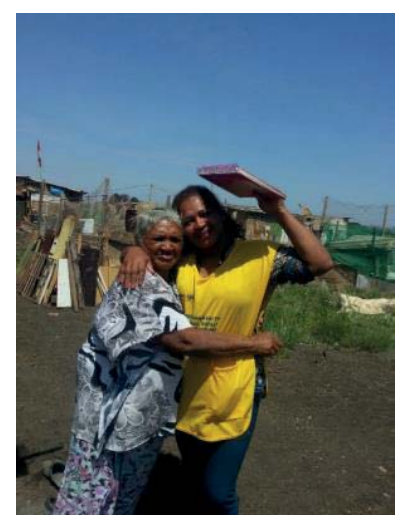

\footnotetext{
${ }^{3}$ I had the opportunity to amply study this involvement process in the United Kingdom during my doctoral research, financed by Fapesp, Process No. 2012/20856-4, Fundação de Amparo à Pesquisa do Estado de São Paulo (FAPESP).
}

Image 2 - A volunteer of the Door-To-Door campaign during a joint community effort in Brazlândia (Brasília).

The collaboration with the switch off project in Brazil began during the study for a doctorate degree. We challenged 10 young adults from São Paulo city's East Zone to organize a community campaign to raise awareness about digital TV, which, the Government had delayed in doing. The young people were members of Intermídia Cidadã, a collaboration pertaining to the Public Communications Nucleus of the Tide Setubal Foundation (NCC-FTAS), which runs a social project in the Jardim Lapenna neighborhood. They immediately agreed to go door-to-door and teach families about how to better prepare for the analog signal switch off. In addition, we created a project called Cidade Adentro to explore interactivity on TV as a tool for social awareness.

After this, a research internship in Italy (Universitá Sapienza) and in the UK (University of Brighton) allowed public identification of policies used to help populations migrate to digital signal. In the UK, the country resorted to an important plan of action to provide technical support for its population during the permanent migration process to digital TV. ${ }^{3}$ It engaged the government, civilians, TV equipment manufacturers, and small businesses. The project achieved relevant results due especially to volunteers who assisted elderly, impaired, and immigrant citizens. (FEITOSA, 2015).

When Antônio Carlos Martelletto, general director of Seja Digital (entity responsible for managing the switch off in Brazil), heard of this research, he decided to design and execute a similar project in Brazil. It was an opportunity to apply the social awareness method to the project and went to Rio Verde (Goiás, Brazil), which was preparing to undergo the analog TV signal switch off in the second semester of 2015. The switch off was initially scheduled for the 29 November, but was postponed to March of 2016. At the end of the process, the Mobilization Management team had recruited approximately 700 volunteers and partners, among which were community, political and religious leaders, as well as educators, artists and university students. It is safe to say that the population, overcome by a sense of solidarity and pure citizenship, took over the project once realizing its public value and nature.

When its switch off process ended, the UK issued a booklet called "101 Stories" ${ }^{4}$ that contained 101 testimonies of the experience through the eyes of team members, volunteers, and beneficiaries. Not that there is any significant competition with the brilliant project executed in the UK, but, it is possible to guarantee that the project in Rio Verde, our first, produced even more inspiring stories than those found in the British document. The challenges faced here are greater: we deal with social vulnerability, poor education, functional illiteracy, and little access to information. Some of these stories were shared on the

\footnotetext{
${ }^{4}$ BBC. 101 Stories: The switchover help scheme/BBC. 2012. Available at: $<$ http://downloads.bbc.co.uk/aboutthebbc/insidethebbc/howwework/partnershi ps/helpscheme/SHS_101_stories.pdf>. Accessed on: November 20, 2016.
} 
"Brazil towards Digital TV" (Brasil rumo à TV Digital) blog 5 that narrates TV's transition process through the perspective of Seja Digital's Mobilization Management team. Therefore, one of the purposes of this article is to share a little of what has been applied to our daily lives and the impact it has made. The results of our initial switch off tests can inspire other South American and African countries with similar socioeconomic profiles to that of Brazil and that will undergo the same process in upcoming years.

\section{About mobilizing and sharing space in the world}

The root of the word "mobilization", widely used by theorists Bernardo Toro and Nisia Werneck [1], comes from the term mobilis, which in Latin means to move or dislodge someone or something from one place to another. According to Toro and Werneck, mobilization stems from a collective desire and shared perspectives and goals. I can say that to mobilize means to leave some form of comfort zone and move towards solidarity, a common good. It means returning to the essence of communal living; leaving gated communities otherwise described by Zygmunt Bauman as places of individual protection, with walls that progressively prohibit the person from occupying and living in collective spaces, and valuing others by opening oneself to the essence of man-man-naturesociety interactions.

This only increases what Bauman [2] referred to as "mixophobia", or "the fear of mixing" (BAUMAN, 2009, p. 43). ${ }^{6}$ This is the opposite of mobilization, especially when taking into consideration Bairon and Petry's ideals on the matter (2000, p. 32): "It is possible to comprehend the totality in which we find ourselves through those around us. To be of this world means to live by pre-giving ourselves to the relationship between subject-object. Therefore, it means to live in the anticipation of any objectivity or subjectivity". In other words, mobilization is to promote dialogue too in order to reach an understanding. It means to mix with others, experience the world, and participate in it through the complete exercise of freedom. It is to position oneself about it, take care of it, share its space, be vigilant and, if need be, fight for it. Civil society, with all its daily demands, offers the ideal place to apply the notion of mobilization. All one has to do is to look at the concept developed by Martín-Barbero and Rey $(2004$, p.90) in the book "The Exercise of Seeing: the hegemony of television audiovisual and fiction". [3]

[Civil Society is] ... a public space where interactions of many different natures take place between different social actors, who are more or less organized. The concept of a civil society is strongly tied to the realities of social debate (in the context of communication), discourse, pluralism, independence to form personal interests, and the ability to reach

\footnotetext{
${ }^{5}$ Webpage: http://brasilrumoatvdigital.blogspot.com.br/

${ }^{6}$ Initially, the architectonic distance within cities and privacy walls of houses were the causes of mixophobia. When Bauman mentions gated communities,
}

social, cultural and political goals. Civil Society is a space of resistance against authoritarianism and the framework for the configurations of cultural policies, the socialization of its citizens, conflict resolution, and the expression of opposition (MARTÍNBARBERO; REY, 2004, p. 90)

In the book Social awareness: One Way of Building Democracy and Participation, Bernardo Toro and Nisia Werneck (1996) [1] emphasize that participating in a social awareness process is "an act of choice", thus an expression of "freedom". According to them, people are "summoned", but the affiliation to a specific project conditioned to the point of view that one has, to the rational way that the person sees him or herself within the process; it is about the commitment to the issue at hand and to the group.

Summoning desires means to summon discourse, decisions, and actions towards a common goal; towards an act of passion, to make a choice that "contaminates" the daily life. Any mobilization is thus towards something, to reach a pre-defined goal, a common purpose, and is therefore an act of reason (TORO; WERNECK, 1996, p. 5)

According to the authors, "desire and awareness" and "action" are the two steps that mobilization depends on to occur within a specific group or community. "The first is of awakening the desire or awareness of the need for an attitude or change. The second is the transformation of this desire and awareness into a readiness of action and the action itself", they explain. (TORO; WERNECK, 1996, p. 43) [1]. According to them, these steps can be experienced concurrently by the members or groups involved in the mobilization project, which can be highly advantageous due to how the current members attract new people to the process by providing real references and assurance that will entice them to join.

In line with Toro and Werneck (1996) [1], the configuration of a mobilization project should provide a list of clear, open, and stimulating suggestions in order that, in the following moment, people may discover and invent new ways to participate, thus avoiding becoming accommodated, feeling manipulated, or somehow sensing that their independence has been compromised. Some steps offered by Toro and Werneck to stimulate people to join a mobilization project, and that objectively help them understand how they may contribute, are as follows: (1)Provide a clear description of the project, its goals/objectives, and the importance of each phase; (2)Pass on a sense of assurance, value, and freedom to act and express oneself in the area he or she participates in because it is important for people to "feel assured of recognition, value and respect for the way he or she is and thinks, no one wants to run

he is specifically referring to the housing models of gated and heavily guarded communities (BAUMAN, 2009). 
the risk of not being understood or rejected" (TORO; WERNECK, 1996, p. 26) [1]. In addition to this, it is necessary that the members feel confident of the actions and capacities shown by others in their respective roles. The delivery of basic materials is a sine qua non condition for the execution of the project. It is also equally important to keep a register of processes, actions, and results and to disclose them in order that all may learn from them.

\section{Social Actors of the Mobilization Process}

\begin{abstract}
Mobilization teaches us to learn to communicate with each other, to recognize the meaning and messages sent, and desire for messages and emotions to be captured (TORO; WERNECK, 1996, p. 59)
\end{abstract}

Toro and Werneck (1996) [1] mention that the ideal mobilization process involves the participation of four types of social actors who understand how fundamental they are for reaching the intended goals of a specific project. These four types are the multipliers, social producers, editors, and social re-editors. Below, a summary is given by the researchers of each classification and examples of how to interpret these concepts within the current structure at Seja Digital.

Social Producer - the institution and/or person that provides the economic, structural, institutional, professional, and technical conditions necessary for the mobilization to happen. . "The [Social Producer] has the intent of transforming the current reality. He has certain goals for change and makes himself available to present and share these goals with others, who in turn will help him clarify, amplify, and of course, reach them." (TORO; WERNECK, 1996, p.22) [1]. In order for the mobilization process to actually happen and reach good results, it is necessary that the social producer respect the principles of democracy, collectivity, and sensibility. He must also have broad knowledge of the reality he wants to change and the good sense to make decisions in collaboration with the editors about the material necessary for the mobilization process. i.e., Seja Digital board of directors and the Seja Digital Mobilization team. The social producer is responsible for identifying re-editors, who are able to reach pre-defined goals and demands of the project and guarantee the distribution of the material to them.

It is essential that the social producer be able to provide guidance to an editor about producing appropriate material and must have thorough knowledge about the possibilities and limitations of using social communication as a mobilization tool. Very often, goals within the mobilization process result in failure because the capacities of communication vehicles and mass communication are underestimated. Positioning the social producer well can guarantee using them to their full advantage.

Editor - embodies how to send out messages; in other words, this entity prepares the communication material and adapts it to different types of languages and media (codes) for the reeditor to understand, embrace, and use in the community. "The success of the mobilization depends on the way that the message is produced and reaches the re-editor's line of work [...] the better [the editor's] knowledge of the re-editor's line of work, the higher the chances of success." (TORO; WERNECK, 1996, p.25) [1]. For this role, one should consider professionals who work in Communications, Events, Design, Creation, and Marketing at Seja Digital.

Re-editor (term coined by Juan Camilo Jaramillo, in 1991) - should have legitimacy and recognition within the community to promote certain messages and adapt them to the current reality of daily experiences. In addition to this, this role summons and prepares the community network to continue the flow of information. Once the entity takes over the message, the reeditor is able to transform the content received by the editor into something that the population can relate to, "through the use of codes, values, and experiences pertaining to that group" (TORO; WERNECK, 1996, p.24) [1], so that they may be convinced of the theme. "He has the ability to deny, transform, introduce, and create meanings for his audience, thus contributing to how it changes its way of thinking, feeling, and behavior." (TORO; WERNECK, 1996, p.24) [1] i.e., NPO's; community, academic, political and religious leadership; educators, teachers, and health professionals

Multipliers - reproduce information in the manner received from the social producer and editor. i.e., Media, Seja Digital volunteers, and young people from Antenista Amigo.

In regards to how the re-editors work to convince people to join the mobilization, Toro and Werneck (1996) [1] explain that the "arguments" tend to become better or modified throughout the process because "everything is alive and dynamic". We can say, based on field experiences that if the project involves different audiences, then we should make arguments according to the demands, needs, and interests of each. For example, we can use different arguments in daily field experiences depending to whom we speak to because the change from analog to digital TV signal may be good for very different reasons to young people, adults, and elderly people. 
Toro and Werneck (1996, p. 45) [1] state that the first three steps needed for planning and preparing a social awareness process are: (1) "structure the re-editor networks", (2) "convert the abstract product into material and messages that can be used in the re-editor's line of work", and (3) "structure the collectivization systems". Four basic dimensions make up the mobilization process: the imagination, line of work, collectivization, and follow-up. These "should be built and operated simultaneously" so that the process may run in its complexity and reach the expected goals and audiences. The imagination links to the goal desired and the paths taken to reach it. "It [imagination] should express the meaning and purpose of the mobilization. It should touch people's emotions. It should not only be rational, but also able to produce passion", Toro emphasizes (1996). The field of work is the location where the actors involved can develop their daily tasks and where they can execute a mobilization project.

According to Toro and Werneck (1996) [1], the mobilization process should also depend on planning and defining not only the roles of the social actors involved, but also a results control plan for evaluating the impacts of its actions and that of the community; in other words, to provide a follow-up. For this to happen, they propose the creation of criteria and indicators that will help social producers and editors understand the results achieved, or decide if it will be necessary to make adjustments to the process, or maybe even come up with new strategies. They defend to build these criteria and indicators collaboratively, "discussed and defined in a democratic manner" (TORO; WERNECK, 1996, p.31) [1]. This must be done among the actors involved, producing social exposure of the project through sharing and distributing its results in order to "maintain the enthusiasm of those involved, stimulate growth in the number of participants, and possibly present arguments for possible funders of the project" (TORO; WERNECK, 1996, p.31) [1].

\section{COMMUNICATION AND MOBILIZATION AT THE SERVICE OF A COMMON GOOD}

A participative mobilization should have, in its essence, a differentiated form and humanized language that brings it closer to the population. In doing this, it generates a feeling of ownership of the process in the actors involved. It also produces spontaneous participation and natural commitment, without seeming artificial or imposed. "Many times, the vehicles and types of materials used in collectivization are the same as those of an advertising or marketing campaign; however, its content is different because it is directed towards a different type of commitment", Toro and Werneck defend (1996, p.30) [1]. Even if they do recognize social awareness as "an act of communication" and communication as an important instrument for collectivization, the authors stress the use of communication is not the only instrument available.

Since we mentioned shared interpretations and meanings, we recognize that social awareness is an act of communication. It should not be a mistake for advertising and marketing, but it does require certain acts of communication in the broad sense. Thus, it can be understandable through sharing process of discourse, visuals, and information. What gives stability to a social awareness process is knowing that what I do and decide within my field of daily work is being done and decided by others in their own lines of work with the same purpose and meaning. (TORO; WERNECK, 1996, p.5)

The authors call "collectivization" or "collective action" that which comes from a common desire and interest in order to reach a goal. "Strength in numbers" is the translation for the feeling defined by Toro and Werneck (1996) [1], which by producing social empowerment, should be valued and fed through a mobilization process. The sharing and promoting of actions is one way to mobilize people, they defend.

What sets collectivization apart from simple spreading of information is its commitment to results. The spread of information is many times for promotional or simply informational purposes. The expected result is that people know or are made aware of the information. Mobilization focus on sharing information (not simply spreading it). The desired result is that people form individual opinions and take action based on these opinions. Furthermore, it is so that the audience feels ownership of the information and passes it forward, uses it, and thus becomes itself a source. It is necessary that all who participate and engage in communicative behavior be interested and willing to receive and give information in order for a mobilization project to be successful. (TORO; WERNECK, 1996, p. 30)

One of the strategies mentioned by the authors to collectivize leadership action is to hand out kits with informative material and identification to the summoned actors (re-editors) for their use. They cite the example of a specific campaign run in collaboration with the leaders of Pastoral da Criança (Pastoral Care of the Child), who received planners and T-shirts with the Pastoral symbol. "When they put on the shirt, they feel and are seen by the community as members of a larger group that transcends community and legitimizes their actions and rewards them with social recognition. [...] They feel connected and develop a sense of belonging". (TORO; WERNECK, 1996, p. 30) [1]

Seja Digital leaders and partners gave the health and endemic agents in Rio Verde campaign T-shirts in favor of the switch off. The artwork design made to accompany health campaigns going on at the time were: November Blue (men's health) and Combat Dengue, respectively. We did this in order to give meaning to their participation in the project. They embraced our 
cause and we embraced theirs. In addition to this, they received a questionnaire to fill out. The questions included the access to digital signal with information on families that they met and talked with. The other volunteers also received T-shirts to officially recognize their participation in the project. At the end of the project, participating leaders in the campaign received a certificate for the hours they had dedicated to it.

\section{THE SWITCH OFF IN RIO VERDE (GOIÁS, BRAZIL)}
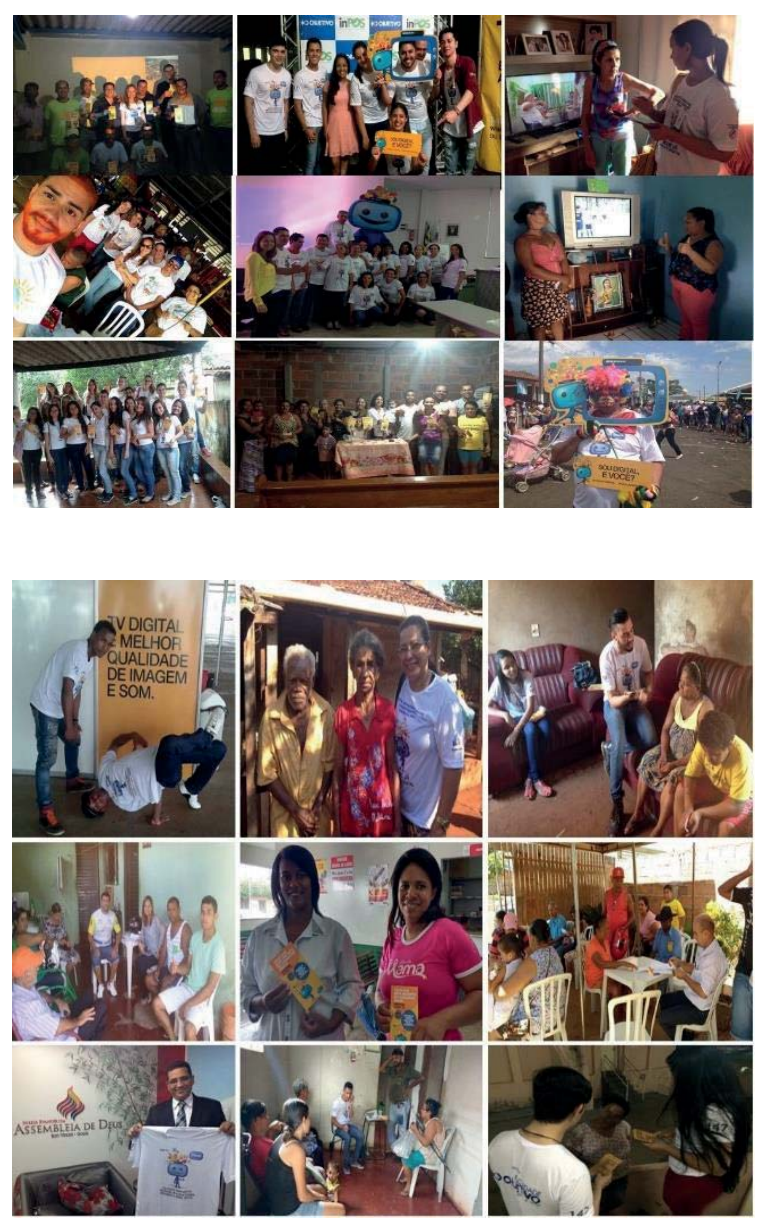

Image 3 - Mosaic with photographs of the mobilization action in "Rio Verde" - Goiás, Brazil (2015 and 2016). Source: Brasil Rumo à TV Digital ${ }^{7}$.

Already considering that the change of TV signal is more than a technological step, we must also see it as more advantageous for the population in terms of image and sound, services, and available possibilities. Therefore, the social awareness project applied in Rio Verde (Goiás, Brazil) contemplated these four pillars: awareness education, humanization of the process, multiplication of the message, and social and digital inclusion. For this, it underwent three strategic phases:

$$
1 \text { - Mapping out local entities; }
$$

7 Brazil in Direction of Digital TV. Available at:

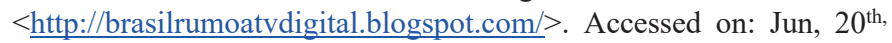
2017.
2 - Bringing these entities into contact with opinion influencers;

3 -Communicational and artistic interventions in favor of the analog switch off (decentralized conversation circles, small forums, participation in open fairs, community events, cultural events, neighborhood cleanups).

In the third strategic phase, we used different types of dialogue adapted to our key audience. Some messages reinforced during discussions were about the mobilization project such as the importance of television in the city's politics, education, and culture; and how television is the only source of entertainment and access to information for many families. We also stressed how fundamental it was for the conclusion of the switch off process for people to participate due to how it depended on their migration to digital signal. It was customary to elaborate collaborative plans in community forums to mobilize the population and take advantage of city events, linked to our partners, to spread our message.

The mobilization project in Rio Verde reached approximately 70,000 people from almost every neighborhood in different city zones. The people were reached through not only the direct actions of Mobilization, but also by parallel actions taken by multipliers and re-editors such as religious, community, and political leaders, as well as university students and health professionals. We are especially grateful for the collaboration of the Assembleia de Deus church, which is the largest and has the highest number of members in Rio Verde. Churches shared and transmitted the switch off schedule shared bulletins and at meetings and services, which were also transmitted on the Internet. Through this medium alone, we reached approximately 20,000 churchgoers, from almost every single neighborhood in Rio Verde. For all this to happen, we had the help of 200-trained pastors. We also received support from local NGOs, the Community Development Council that unites all neighborhood associations, approximately 140 Public Communications and Medical students from the University Rio Verde (UniRV) and Objetivo University, 118 health and endemic agents, and 30 art educators from the Municipal Secretary of Youth (capoeira, hip hop, percussion and graffiti instructors).

\section{Health and Endemic Agents}

We ran a two-week campaign in October in collaboration with the Endemic Health Agents and their coordinators. They introduced the switch off theme in their daily home visits. They talked about digital TV, answered the population's questions, distributed informative material, and scheduled times to pick up converter kits distributed by Seja Digital for families enrolled in federal government social programs. For this, we received the help of 118 professionals. This campaign alone reached 
approximately 16,100 families. Note that a great number of participants agreed to continue collaborating with the project up to the analog signal switch off.

The campaign had an important role in the process, especially when taking into consideration the strategies defended by Toro and Werneck (1996) [1], who understand that although mobilization should not limit itself nor be understood as a temporary campaign, it as a way to consolidate actions and bring exposure to the project. All actions are valid and many require very little if any financial resource. As the number of partners grew, doors opened, especially because people now understood the purpose of our work and grew to value it, contemplating its social value. At the end of the process, we even promoted events that resulted in rewards for the partnering entities.

The health and endemic agents that participated in the campaign reported that they sensed a lack of solutions for the more needy population that would not receive free converter kits. According to them, these families continued to complain about the high cost of the essential equipment needed to digitalize TVs and lack of public policies that assist those who are not eligible for Bolsa Família (Family Purse). (Note: Many families did not have enough credit to buy converters). Seja Digital was authorized to distribute converters to families enlisted in the Cadastro Único, a list of families that benefit from federal government social programs. This solution was extremely helpful. The mobilization will have greater effect and return when, in addition to supporting families during the migration process and making them aware of the distribution of converter kits, we also provide practical migration solutions for those facing difficulties and who do not fall under the necessary categories of social programs. Perhaps we can make a partnership with banks to finance the costs purchasing equipment. $^{8}$

According to reports given by participants, our actions, especially that of collaborating with health agents, served to give direction to many families about where to purchase converters, the price of gadgets, and what to do in order to migrate to digital signal. They told us that they met with many families who knew about the switch off, but did not know how to prepare themselves for it. This is why meeting face-to-face is so important. According to the health professionals and the experiences that we had with other volunteers and field partners, the questions that most families asked were "I have a satellite dish. Will I not be able to watch TV after the land analog signal switch off?", "How do I tune into digital channels?" and "What's the ideal antenna for where I live?"

Also based on the experience in Rio Verde, we noticed the need to establish partnerships in the other clusters through agreements, be it with universities and other institutions. This allows for the role of each and project goals to be well established. We also came to realize that in order for the health professionals to do their part and for the mobilization team to have access to public devices, the correct manner is to establish an agreement with the city executives, taking into consideration the project's nature of public use.

In addition to T-shirts, Seja Digital also gave a converter kit to each health and endemic agent and called them "enabling kits". Through these, they had the opportunity to learn how to practically use and install the equipment in order to teach the population better. The outskirts of the Federal District copied this action. One thing that caught our attention is that due to the communal health agents, the Strategic Family Health stations (ESF's) also became, in a spontaneous manner, locations in neighborhoods where people could get information about digital TV.

It is important to note that we received fundamental help from local communication vehicles (radio and TV) that helped spread the news on the analog signal switch off. The reporters' performance in local media was essential to spread the word about Seja Digital's mobilization actions and, at the same time, legitimize our work with partners in this territory. We would like to highlight TV Anhanguera, associated to Rede Globo Goiás that followed up on us on an almost daily basis.

\section{Some observations from field experiences}

- It's important that the scheduling posts be amplified and as close as possible to the population;

- It is clear that the volunteers' work is not only fundamental and essential, but also that its success does not always depend on them alone. Specific mobilization processes such as this need to be able to rely on different partners and strategies;

- The performance of health and endemic agents and Center of Public Assistance Reference (CRAS) professionals offers great potential to execute Seja Digital's Mobilization project in large scale all across Brazil. In order for this to happen, it is important that this front be explored in the following clusters because they know the families well and have earned their trust;

- The results of the scheduling action at health stations show us that these locations (in collaboration with the health and endemic agents in the community) can be important locations for spreading our campaign message and a great alternative to gain proximity with families receiving the kits (and even those who don't) at different places in the city;

- Religious centers are fundamental allies in the process of spreading information about the switch off;

- The most convincing argument we've used to convince young people of our campaign has been that the switch off will favor the quality of service in $4 \mathrm{G}$ broadband and access possibilities offered through digital technology;

- Using cars with speakers installed in them is still a strategic medium to use in the mobilization campaigns due to the

\footnotetext{
8 A first step could be financing converters, with automatic payroll deduction, for public employees whose salaries are equal to three minimum wages.
} 
immediate impact they have. In Rio Verde, we used them to inform people about the locations where they could schedule to obtain their set-top box;

- Community leaders add a lot of value to our work and give credibility to what we do in the citizens' eyes. Fifteen neighborhood leaders in Rio Verde opened their homes for us to do the scheduling campaigns. They performed home visits to answer questions, spread the word about converter kits to families registered in the Cadastro Único (Single Register) program, and some even installed antennae in the homes of lowincome families and elderly persons. We also received reports of leaders who drove senior citizens to stations to pick up their kits. These partnerships have contributed significantly to mobilizing the population and spreading information about the Cadastro Único program and the NIS number, two resources that many times are unknown to the population;

- The support we received from the public education system management and actions held at educational institutions were significant for spreading information and awareness of the switch off project and news about the technological characteristics of digital TV;

- Volunteers are a driving force for Seja Digital Mobilization because they stimulated new actors to enter the migration campaign process. They were an important source of switch off information and support for the population and added credibility to our local work. After some time, volunteers were able to work independently and only reached out to us if they had any questions themselves;

The philanthropic entities have a huge influence over the lowincome population and those with less access to information, such as the elderly, those with any form of impairment, young people in high-risk situations, and children from low-income families. For example, they helped us locate and contact families who were eligible to receive the kit but had not known about it until then.

I would also like to mention that when we take a look at the scope of work proposed for the Seja Digital Mobilization Project in Rio Verde, it is clear that all suggested projects were executed and that the courses of action taken were the best. The best part of it all is that the "real" experience in Rio Verde showed us various dynamic ways to switch off the analog TV signal in the task still to be completed and accomplished throughout Brazil.

\section{NEXT STEPS: FEDERAL DISTRICT AND}

\section{SURROUNDING CITIES}

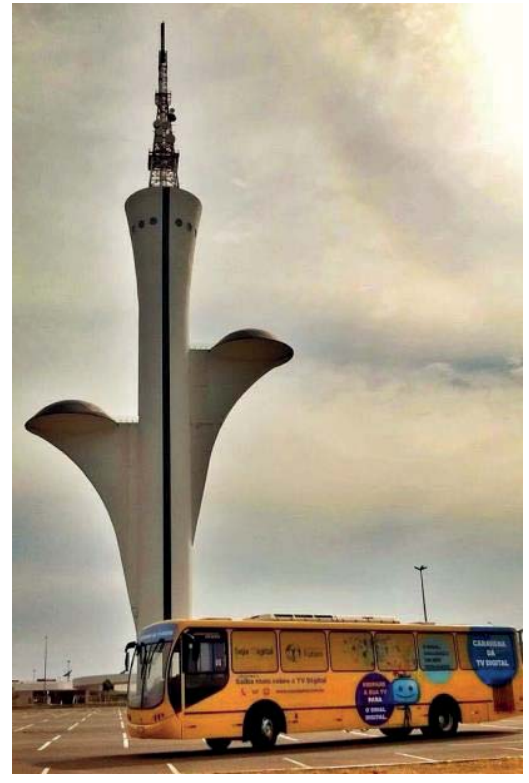

Image 4 - TV Digital Tower in Brasília, better known as "Flor do Cerrado" (the Savannah Desert Flower).

In light of the success obtained by the social awareness switch off Project in Rio Verde, Seja Digital has amplified its project in Brasilia. A team was hired to capitalize on the potential of the message outreach and establish goals. A specific work plan has been designed, new projects created and adapted, agreements have been established with many partners, including 9 counties surrounding and in Brasilia; all this to enable the project currently underway. We later amplified and structured the project developed for Brasilia and based it on the experience in Rio Verde. We also collaborated with a team that created its execution strategies that were aligned with the basic principles defined by the local mobilization team:

1. Promote collaborative performance between mobilization team and partners.

2. Form multiplier groups able to spread the message and support the more vulnerable population during the digitalization process through qualitative, collective, and sustainable actions.

3. Create projects that we can reproduce in other clusters and use resources and attractive strategies of high, social interest that promote the execution and reaching of established goals.

4. Optimize human, natural, material, and financial resources.

5. Integrate the performance of all work groups at Seja Digital.

6. Value and include less privileged persons.

In addition to this, we thought of a few performance strategies:

1. Promote informative, entertaining, and motivational projects, training, and projects that 
have social interest to capture the public's attention.

2. Identify and contact public and private institutions (including NPO's) that develop activities targeted towards low-income families.

3. Optimize on existing events and meetings like associations, councils, and church meetings.

4. Explore environments to hand out media and pamphlets, such as banks, urban ecological parks, health stations, hospitals, local businesses, CRA's, farmer's markets, and neighborhood restaurants ${ }^{9}$.

5. Infiltrate certain territories by means of community leaders, confirming their legitimacy and trustworthiness, in addition to promptness to adhere to the process of spreading information.

Description of the main projects applied to the Federal District and its surroundings:

1. Door-To-Door: campaign led by health professionals and volunteers to provide orientation to families about the migration to digital TV and the switch off process during home visits. In the Brasilia cluster, the campaign relied on the help of 830 health and endemic professionals from 7 counties. It also received the collaboration of 2,296 volunteers from Brasilia to inform families about the migration to digital TV and the analog signal switch off. Health professionals used the daily home visits to provide the population with support during the migration to digital signal, informing them about how they could receive free kits from Seja Digital and instructions for installing the equipment. The total number of homes that were directly impacted by this movement is 97,9660 .

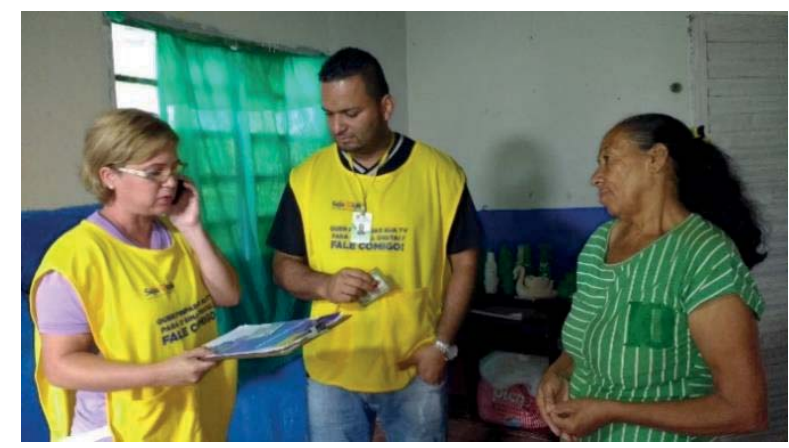

Image 5 - A patient finds out during a health agent's home visit that her name is on Seja Digital's list to receive a free converter kit.

2. Community Dialogues: an initiative designed to involve community leaders with the campaign supporting analog signal switch off. Two NGOs - R.U.A.S. and Planning the Future - were important partners that supported us in each of the cities and neighborhoods we tended to in Brasilia. These mobilized NGO leaders were responsible for spreading information at local gatherings such as homeowner association meetings, religious events (mass and church services), senior citizen meetings, CRAs, and health centers. They helped us engage with communities and contributed to events promoted by Seja Digital. The NGOs organized the mobilization, selection, and training phases as well as defined and followed up with each leader's impact group. Each leader was expected to promote and participate in at least 3 (three) weekly meetings and 1 (one) monthly, community collaboration. Seja Digital's Mobilization team also received support from neighborhood presidents, leaders of diverse religions and spiritual centers, educators, and representatives from associations focused on community assistance.

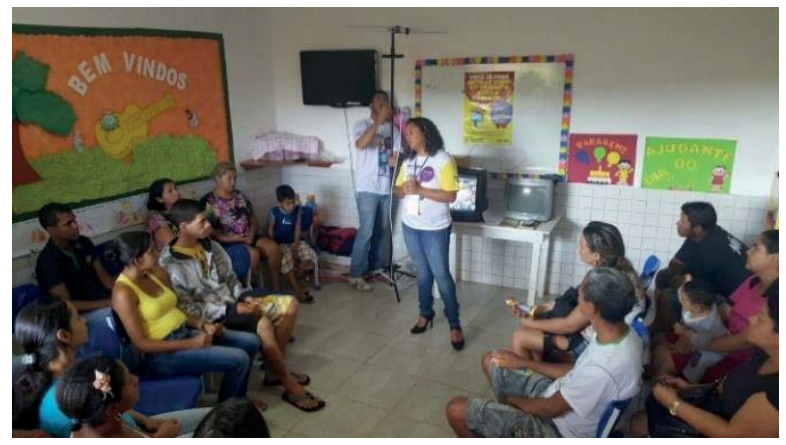

Image 6-Community Panel by the leaders of RUAS in the

"Estrutural” (Brasília) neighborhood during a Parent-Teacher meeting.

3. Seja Digital Volunteer Campaigns: events held to spread information with the help of volunteers. Marquinhos Soares, of Seja Digital's mobilization team, mobilized the volunteers from Brasilia. They got together and formed a body of people to spread awareness to populations in areas with average flow of information (businesses, fairs, bus stations, cultural and sports events, subway stations, neighborhood parks and restaurants) or going door-to-door.

\footnotetext{
${ }^{9}$ The government established a restaurant project in Brasilia to offer meals at affordable prices to low-income families.
} 


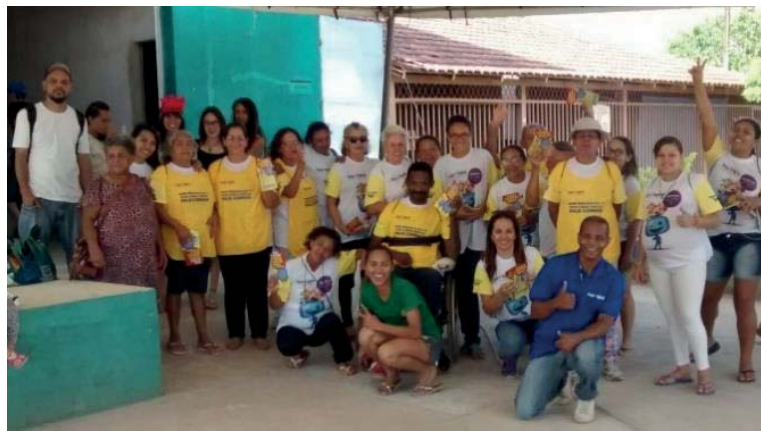

Image 8 - Volunteers from "Vale do Amanhecer" neighborhood in Planaltina (Brasília) during a Door-to-Door community campaign.

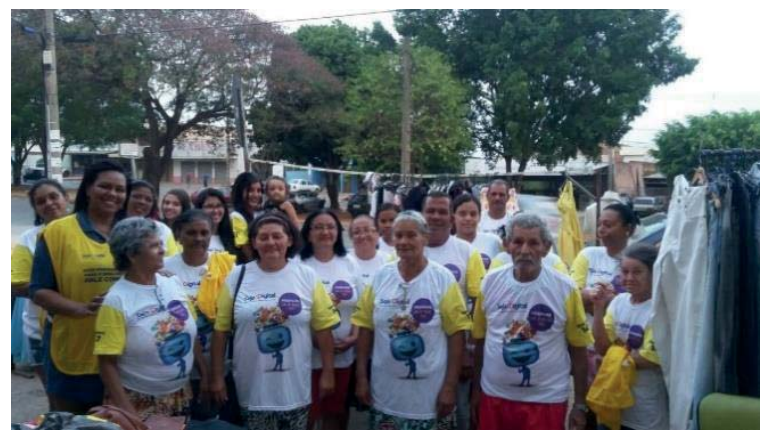

Image 7 - We rely on the participation of many senior citizen volunteers, especially women. In the image, volunteers from "Planaltina” (Brasília) during a neighborhood campaign.

4. Community Counseling Centers: strategic locations in more vulnerable neighborhoods with an average flow of people that guided the population and informed them about obtaining free kits. The senior citizens involved in the Melhor Idade (Golden Age) Digital program led this movement. Seja Digital established 12 Community Counseling Centers in neighborhoods with lesser digitalization. These centers received elderly citizens selected by the Melhor Idade Digital program devised by Seja Digital to involve senior citizens in the switch off mobilization campaigns. Our general-director, Antônio Carlos Martelletto, was inspired by initiatives promoted by the Canadian government aimed at stimulating volunteer work among senior citizens. It is a way of respecting them, allowing them to exercise their rights as citizens, and giving value to their participation, making them feel important and needed by the project. The intention is to also transform the migration project to digital TV into an opportunity of inclusion and digitalization because each participating volunteer received a free converter kit and so became digitalized! The United Kingdom developed a similar project.

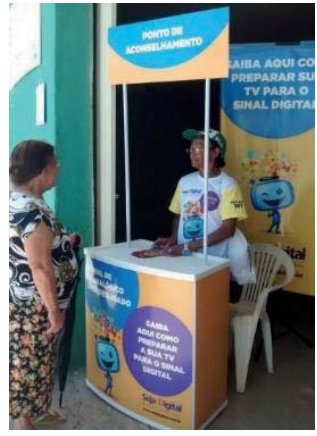

Image 9 - Volunteers in action at PDA located at PIMEV ${ }^{10}$, a "Vale do Amanhecer" entity (Planaltina - Brasília).

5. Digital TV Caravans: a community communication tool dedicated to providing interaction with the population. Events held in neighborhoods and schools:

5.1 Caravans at School: activities directed towards public school students and employees with the intent of making them aware of the complete migration to digital TV. This was the solution that Seja Digital found for this particular audience to spread the news to family members and friends and inform them about how families who benefitted from federal government social programs could obtain free converter kits. The activities offered by 120 caravans influenced in all, 40,000 students in all. The events lasted up to 2 hours and were held mornings and afternoons for elementary schoolchildren. They learned about tuning the digital TV signal in the "Sintonize-se" "(Tune in)" workshop and how to prepare for the analog signal switch off through fun cultural presentations.

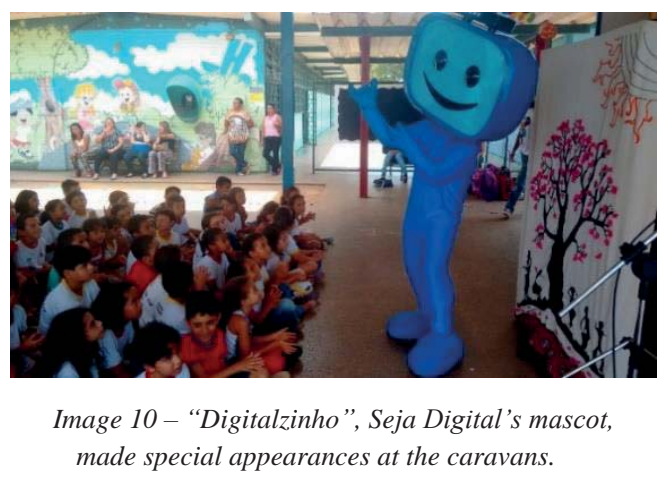

5.2 Neighborhood Caravans: this involved a custom-made bus equipped with handicap access and TV sets that showed the difference between transmission by analog and digital signal. The "Sintonize-se" workshop informed visitors about how to install the converter kit and tune the channels, inside the bus. The event included skits, dance presentations, workshops on art and urban gardening, hair cutting services, blood pressure measuring, graffiti presentations, character drawings, and face 
painting. These caravans circulated mainly through open markets on weekends. It was a great opportunity for the community to verify if it could have access to the free converter kits. If so, people could schedule right then and there to receive the necessary equipment. Some caravans even offered transportation services to locations where the population could withdraw kits and go home practically digitalized. One of the audience's favorite characters was the Digital mascot, who helped get observers excited and interact with the percussion group, Batuque Cerrano. In addition, the caravan also made collectors available where people could consciously dispose of electronic waste or unused or broken TV sets. The NGO, Programando o Futuro (Planning the Future) supported this caravan.

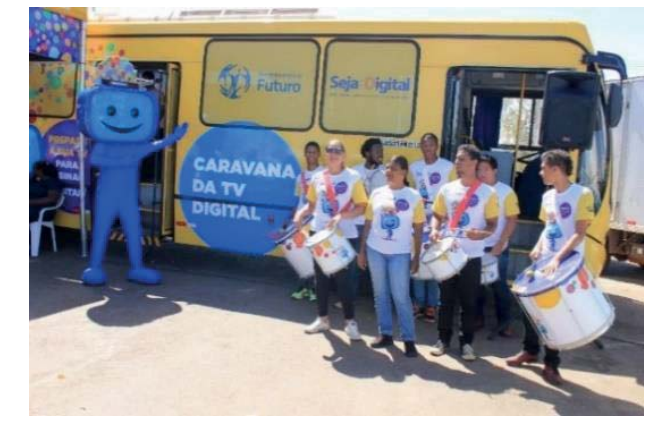

Image 11 - The percussion band "Batuque" no Digital paraded with the caravans in the neighborhoods.

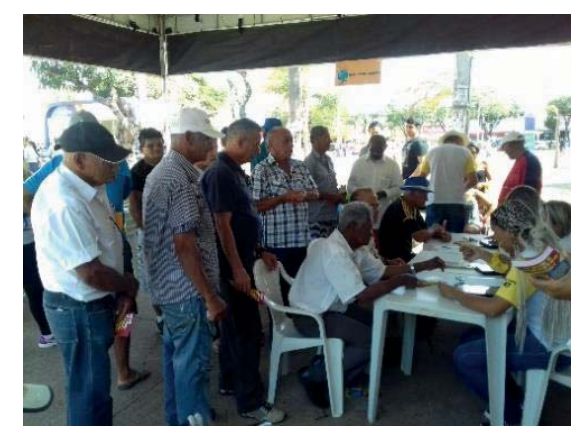

Image 12 - Results from the caravans: 17,000 people serviced and over 50,000 reached.

6. Academic Mobilization: an interdisciplinary project that engaged university students and the academic community in the analog TV switch off. This project, executed in partnership with the Catholic University of Brasilia (UCB), rallied the academic community to the analog TV switch off movement and influenced about 7,500 people. In order to get them involved in the switch off process in the Federal District, Seja Digital held a convention in partnership with UCB. The project was named "Migration to Digital TV" (MTVD) and relied on the participation of professors and students from the schools of IT, Social Communications, Languages, Education, Medicine,

\footnotetext{
${ }^{11}$ Within the seven basic lessons for an education on social interaction, by Toro e Werneck (1996, p.61), are "Learning to interact socially means,
}

Dentistry, Healthcare, Social Services, and from the postgraduate "strictu sensu" Masters in Communication program. Alexandre Kieling (from the Department of Social Communications and Journalism) directed the project and brought together 681 students (22 scholarship receivers and 659 volunteers) that directly and indirectly assisted in routine academic activities and contact with the regions in which they lived.

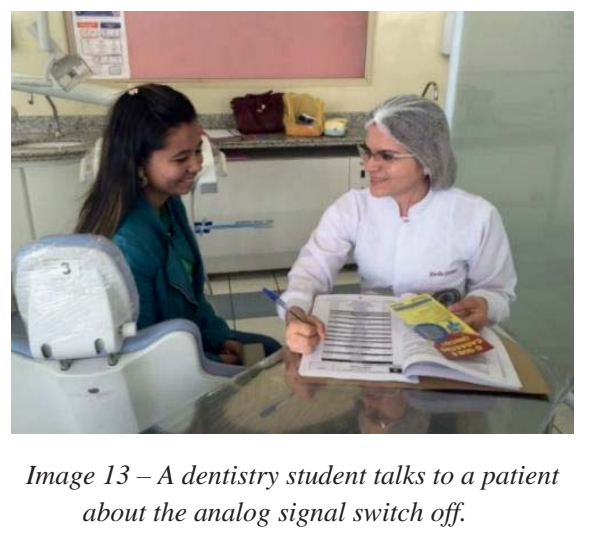

7. My Old New TV Campaign ${ }^{11}$ : a campaign directed towards reducing socio-environmental risks resulting from the inappropriate disposal of old TV sets, which may increase with the switch off processes. In addition to informing the population of the risks of throwing out old devices inappropriately, the campaign encouraged the donation of old equipment and collected them at 50 different drop-off points throughout the cities of the Brasilia cluster. Another NGO, Programando o Futuro reconditioned the old equipment and later donated to families who received the converter kit, but did not have TVs at home. The cathode-ray tube in television sets, made up of heavy metals such as lead and mercury, can be extremely toxic. They cause high levels of land and river contamination if they are disposed of and dissembled incorrectly. For this reason, if they cannot be re-used, they need to be destroyed by companies specialized in the matter and that use the necessary techniques to decontaminate the TV screen. Once crushed, it is used to manufacture flooring, ceramics, tiles, and paint used for road markings. We collected 1,894 TV sets total and reconditioned 26 of them. All this generated a volume of 39,123 tons of residue. Seja Digital's project of disposing electronic waste currently counts on partners throughout the entire country. One can find the closest drop-off point by typing in his or her zipcode on the sejadigital.com.br/recicle webpage.

foremost, to learn to be in the world". According to them, social interaction means taking care of the environment and accepting that we are all part of it. 


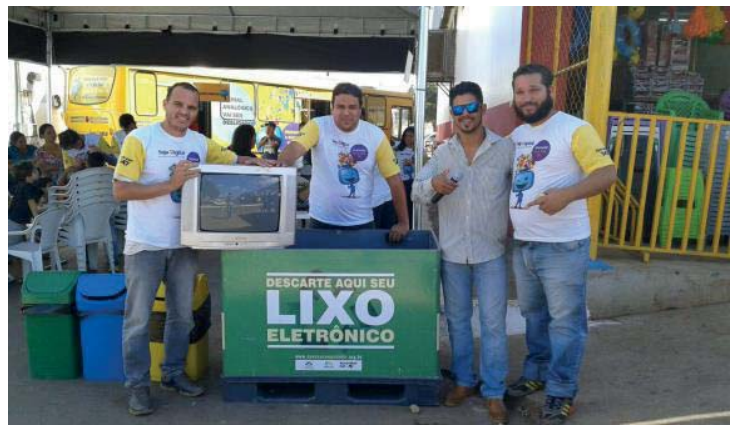

Image 14-TV Digital's Neighborhood Caravan is also a movement to collect electronic waste.

8. Outstanding Social Mobilizer Award: motivational strategy/incentive for volunteer teams to encourage the qualified and continuous participation of different teams in the mobilization project such as NGO volunteers, health professionals, health and endemic agents, community leaders, university students, and Antenista Amigo (Antenna Technician Friend). This participant relation is away to recognize all those who stand out in their participation in our project. 9. Antenista Amigo ${ }^{12}$ : professional training for people in the community to meet the growing demands of antennae and digital TV converter installation services. The project aims to create employment and income opportunities, making it possible for lower-income families to hire the services of an installation technician. It also seeks to support families and neighbors by installing the converter kit free for a limited number of those who receive support from federal government social programs and raise awareness on how to avoid home accidents caused by people installing the antenna on their own. Proeletronic, a Seja Digital partner, trained ten students from the Ceilândia campus of the Federal Institute of Brasilia (IFB), most from the School of Electronics. They went on to offer workshops for 351 people in the community. These were free of charge and each participant earned a tool kit at the end of the course to work with installing antennae and converters. In return, each technician received the mission of digitalizing 10 low-income homes. Thus, we estimate that 3,510 families benefitted directly from this project.

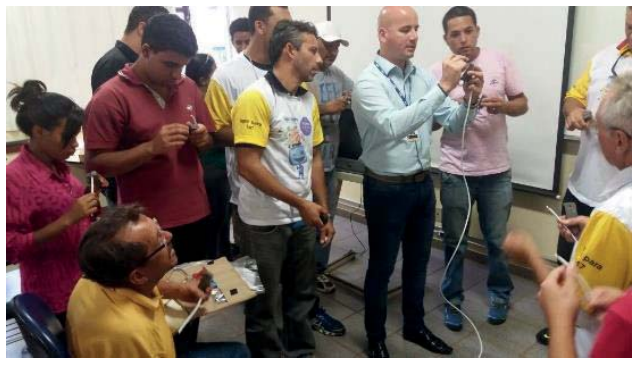

Image 15 - A technician from Proeletronic, a partnering company, teaches the students.

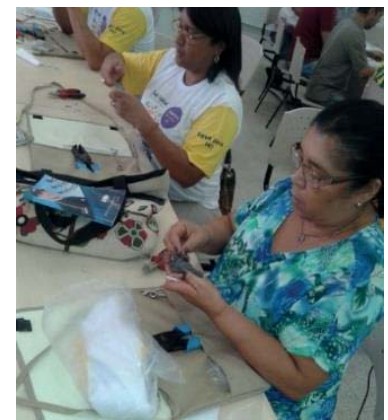

Image 16 - Women were important participants in the project.

10. Training: conceptual and technical training for all digital TV volunteers and project partners. We created a Social Mobilizer Handbook ${ }^{13}$ and a Pocket Guide ${ }^{14}$ that contains information on how to better support communities. In all, we offer 160 qualifications.

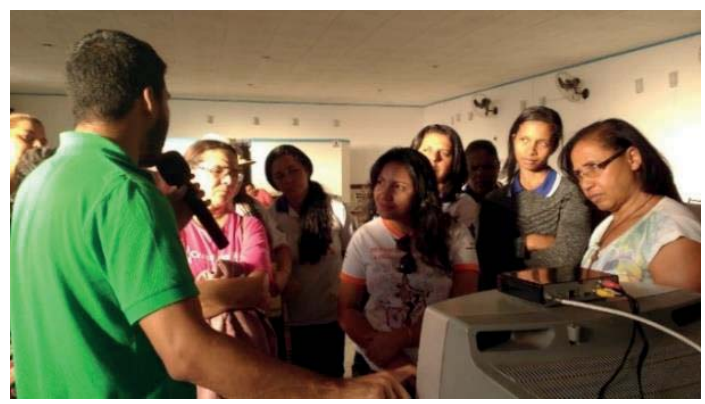

Image 17 - Training for health agents from Cristalina (Goiás).

Social Development Secretariat Campaigns: Seja Digital's Mobilization team executed an important part of the job in partnership with the Social Assistance Reference Center (Cras), Bolsa Família, and neighborhood restaurants. The information given to the families reached by these outlets was about how to schedule to receive the free converter kit from Seja Digital. For example, in the Brasilia cluster, 123 Cras

\footnotetext{
${ }^{14}$ Available at:

$<$ http://www.sejadigital.com.br/pdf/sejavoluntario/perguntasfrequentesguiade

bolso.pdf $>$. Accessed on: Jan, 10 ${ }^{\text {th }}, 2017$
}

\footnotetext{
12 "Antenista Amigo" refers to the antennae installation technician.

${ }^{13}$ Available at: <http://www.sejadigital.com.br/pdf/sejavoluntario/guia-domobilizador-02.pdf $>$. Accessed on: Jan, 10 ${ }^{\text {th }}, 2017$
} 
employees, joined our cause and thanks to them, we reached almost 90,000 families.

11. Escuta Jovem Digital: a get-together organized to understand young people's perspectives and their different languages from cities involved in the switch off process to better deal with the information received during our group communications campaigns. In addition to respecting and recognizing each community's language style, the initiative legitimizes its participation in our project and plans to generate a sense of ownership by basing itself on the premises of participative, engaging, and two-way communication and mobilization.

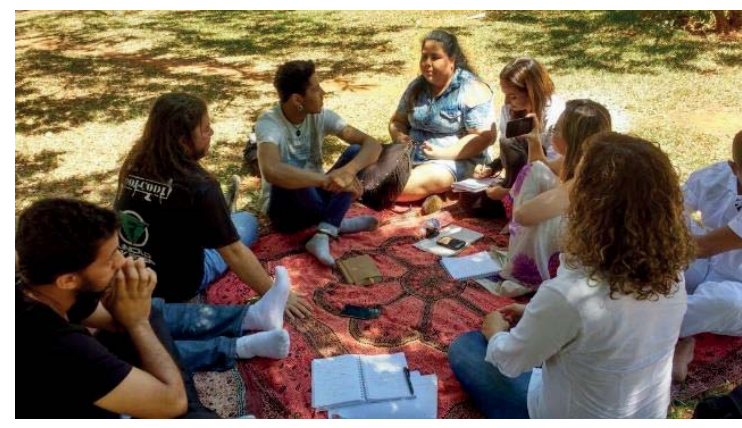

Image 18 - We talked to young people and adults in Brasilia about the TV Reflexo Digital project. ${ }^{15}$

12. Digital Student Contest: a fun and educational strategy for motivating the public school community, and especially elementary students, teachers, and employees to get involved with the switch off process and spread the news about the distribution of free converter kits. It is a way to value the cooperation of these individuals and, at the same time, a request made by Seja Digital to know more and explore the theme better. It is also a call for these participants to lend support to those who need it the most, providing them with the knowledge of the changes that are happening in the scenario of TV technology in a didactic, clear, humanized, and loving manner. In the Brasilia cluster, children explored the theme, "Go Digital" and "Leave No Man Behind! Brazilian TV Will Be Completely Digital". The purpose was to emphasize the analog TV switch off date in the Federal District and explain the advantages of digital TV. The competition awarded the following categories: drawing, video, jingles, and essay writing. The winner of each category won a 42-inch screen TV.

\footnotetext{
${ }^{15}$ The TV Reflexo Digital project began at a public school in Recanto das Emas as a means to discuss the relationship between Education and Communication. The project's main purpose is be a virtual environment
}

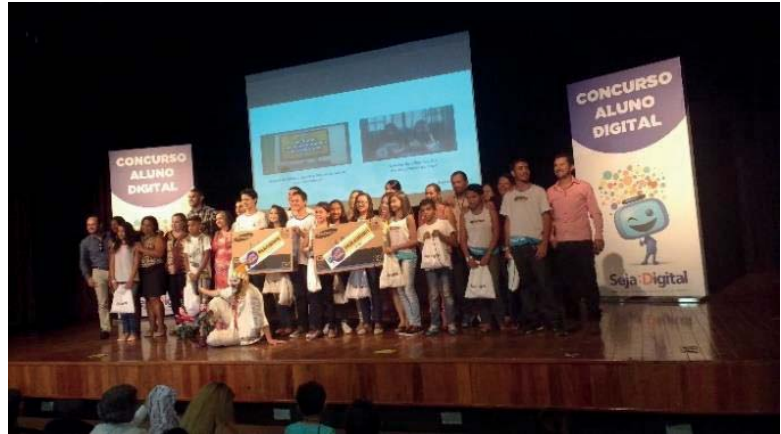

Image 19 - Winners of the Digital Student Award.

\section{FINAL NOTES}

Daily life is that which is given to us each day (or that is ours to share); it pressures us day after day, overwhelms us, because there is a present oppression. [...] Daily life is that which intimately binds us, from the inside out. [...] It is the developing story about us, almost in withdrawal, sometimes hidden. What interests the daily historian is the invisible (DE CERTEAU, 1996, p. 31) [4]

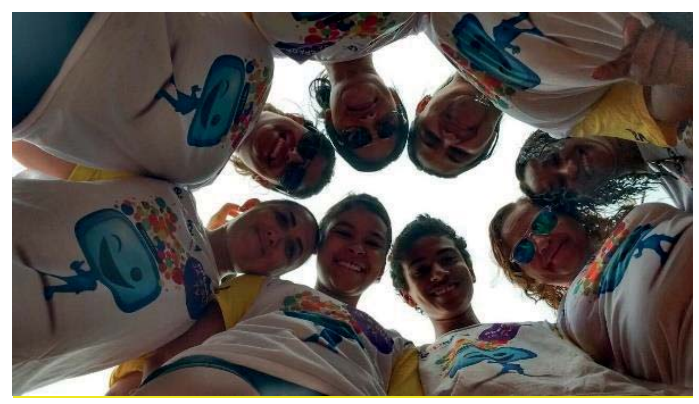

Image 20 - Campaign volunteers at Trecho III - Sol Nascentel Ceilândia, in Brasília: All together so that no one gets left behind.

Jesús Martín-Barbero and Germán Rey, in their book Os Exercícios do Ver: hegemonia audiovisual e ficção (The Exercises of See: audiovisual hegemony and fiction), defend that the potential that exists with TV goes beyond what we explored in the past few years, within the cycle of transmission and receipt. "[...] some fictional authors [...] start to understand that television is not a mere instrument of diffusion, but a medium of its own expressive properties; a medium searching for its own language (MARTÍN-BARBERO; REY, 2004, p. 155) [3]. This search seems to be only beginning. Arlindo Machado (2000) [5], in the book Television Taken Seriously, offers us a strategy for looking at this medium differently,

where young people, students, and former students from the Ensino Médio (High School) 111 Center ("Recanto das Emas"), can produce, spread, and share information. 
similar to what was done with cinema and literature, so that it too can be analyzed from a positive point of view: "It's all a matter of changing one's focus. Instead of paying attention to the lesser forms of television, the idea is to change focus to the highlighted differential, which expands the expressive possibilities of this medium" (MACHADO, 2000, p. 10) [5]. Machado understands that only after we remove the social prejudice against television, especially in part of intellectuals, technologists, and sociologists, will it be possible to discover potentials that go beyond those that offered by it so far. All our mobilization campaigns have this concept at their core and leave the population with this question: What can we do to have the TV we desire? The communities reflected upon this question with us and they understand that we already have the technological means to meet the request.

Martín-Barbero and Rey (2004) [3] put communication as an instrument to obtain exposure by society. It is able to promote debates, raise questions, search for different interpretations about facts, and multiply the different means of social debate and the quality thereof. They recognize, however, that this is not a rule because interests also direct communication. "[...] communication has distortions, restricted fields of expression, themes that are still intentionally left in the shadows." (MARTÍN-BARBERO; REY, 2004, p. 86) [3]. When they wrote the book, 11 years ago, they realized the need of a plural environment for collective expression that would be able to fill in civil society's communicative blanks, one that is difficult to find in mass media, according to the following statement. "The consolidation of an 'us' in civil society in the face of authoritarian manifestations, the formation of a common space for revelation where civil society expresses itself without plurality, are challenges that currently collide with the media in search of exposure." (MARTÍN-BARBERO; REY, 2004, p. 87).

Seja Digital's Social Awareness project is a place for this. An environment that is sensitive to the population's communitarian awareness and its ownership of the digital TV migration process. It's a tool made by the community for the community. We opened a channel of a discussion so that this involvement occurs in the most effective way possible to generate commitment, love, participation, and a sense of collectivity. I can guarantee that all this adds value to the process; it adds humanization, stimulating popular imagination, because it is true that television is still dearly beloved by Brazilians. My observation is that social agenda has a lot of power. It allows the population to own the process and sees it not as a simple technological change, but a project of public use that can only be accomplished through a chain of solidarity and by collective effort.

This project makes it so that, by using different public communication tools and languages, we establish a connection between city and citizens. We are doing an "urban exchange program" (in the words of Martín-Barbero and Rey [3]) between TV digitalization processes and its members, updating them about the latest local events that will affect their daily lives. The experiences of this mobilization carry beautiful stories of daily life and relationships that families have with television. In almost two years since we began the race towards the analog signal switch off, we have experienced touching stories and already have so much to tell about the following chapters of this historic process now happening in Brazil.

Rio Verde, the Federal District and surrounding counties were enormous learning grounds, with favorable conditions for building beautiful partnerships and friendships. In all, it is a place with welcoming people. They are willing to help each other. Our partners and volunteers dedicated hours, even weeks, to our project in order to guarantee that a portion of the population would have the opportunity, if not the right, to open television signal, a public asset that is free and for all Brazilians.

The analog signal switch off in Rio Verde reached exceptional conditions and $93 \%$ of the goal established by Anatel and MCTIC. After suffering two postponements, the switch off was authorized and $87 \%$ of homes are now digitalized. We noticed that a part of the population showed a certain level of wariness, strongly resisting the conversion. Furthermore, the distribution of free converter kits had been initially limited only to families that were registered in the federal government social project, Bolsa Familia. The change to include those registered in the Cadastro Único program, a mere two months away from switch off, made a big difference. One month after switch off, a survey commissioned by Seja Digital performed by Ibope pointed out that only $2 \%$ of Rio Verde's population were yet without access to television.

Between January and November 2016, Seja Digital proposed the aforementioned projects in order to provide support during the migration phase of analog to digital signal for the population living in the Federal District and 9 surrounding cities in Goiás (Valparaíso de Goiás, Novo Gama, Cidade Ocidental, Luziânia, Cristalina, Formosa, Planaltina de Goiás, Santo Antônio do Descoberto, and Águas Lindas). Almost 5,000 volunteers, among which were 2,296 community leaders, 120 schools, and 4 partnering institutions (Programando o Futuro, R.U.A.S., $\mathrm{UCB}$, and IFB), collaborated with 11 projects that aimed to inform, mobilize, and prepare all layers of these cities for the analog signal switch off. Through this, we reached 650,000 people directly and contributed to the Brasilia cluster switch off process. The Federal District and surrounding cities switched off 22 days in advance, and reached $92 \%$ of digitalized population. (Ibope, 2016). Two month after switch off, a survey requested by Seja Digital showed that $99.44 \%$ of the population had access to television signal. In other words, only $0.66 \%$ could not watch TV.

This success is the result of work done by many hands: partners, volunteers, and Seja Digital teams (Logistics, Engineering, Management, Legal, Purchasing, Customer Service, Events, and Communications) that diligently and daily applied themselves to guarantee that the more needy population would be included in the digital signal migration process. These people gathered hundreds of families to the heart of our project, lifted them up, and truly did not leave them behind. Thus, the digitalization process is now complete in Rio Verde, Brasília, São Paulo, Goiânia and its metropolitan regions. Our journey 
has only just begun and we still have many roads to travel on before the entirety of Brazil is finally digitalized.

"We have noticed that when we make people aware of how important television still is for many families; when $I$ argue and accept that we will never achieve our goals on our own and that we need everyone's help; when I realize that volunteer roles are essential to guarantee that these families have access to TV signal; the actors feel valued and important to the process and begin to collaborate more freely and passionately".

\section{REFERENCES}

[1] J. B. Toro and N. M. D. Werneck, (1996) Social awareness: One Way of Building Democracy and Participation. Available on-line at http://www.compreender.com.br/gestao/files/biblioteca/5b1eeb01411d764ed1 046eea1b92be10.pdf

[2] Z. Bauman, Trust and Fear in the City. Translated by Eliana Aguiar. Rio de Janeiro: Jorge Zahar Ed. 2009

[3] J. MARTÍN-BARBERO and G. Rey, The exercises of seeing: audiovisual hegemony and television fiction. Translation by Jacob Gorender. 2.ed. São Paulo: Edit. Senac, 2004

[4] M. de Certeau, The Invention of Daily Life: The Art of Doing. 21. ed. Petrópolis, RJ: Vozes, 2014

[5] A. Machado, Television Taken Seriously. 4. ed. São Paulo: Edit. Senac, 244 p., 2000

[6] D. F. Feitosa (2014) Television in the Age of the Digital Convergence of Media. A reflection on public communication. 2015. Thesis (Doctor in Communication Theory and Research) - School of Communications and Art, University of São Paulo, São Paulo, 2015. Available at: $<$ http://www.teses.usp.br/teses/disponiveis/27/27152/tde-24112015-101553/>. Acessed on: May, $27^{\text {th }} 2016$.

[7] BBC. 101 Stories: The switchover help scheme/BBC. 2012. Available at:

$<$ http://downloads.bbc.co.uk/aboutthebbc/insidethebbc/howwework/partnershi ps/helpscheme/SHS_101_stories.pdf >. Accessed on: Nov, 20 ${ }^{\text {th }}, 2016$.

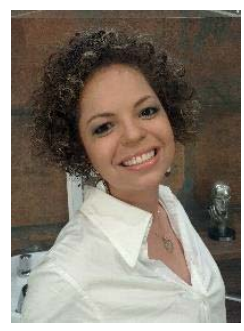

Deisy Fernanda Feitosa. Graduated in Social Communication - Radialism (2007) and Journalism (2009) by the Federal University of Paraíba (UFPB), has a Masters degree (2010) in Digital TV: Information and Knowledge from the Universidade Estadual Paulista Júlio de Mesquita Filho (Unesp), and received a $\mathrm{PhD}$ (2015) in Communication Sciences by the School of Communications and Arts at the Universidade de São Paulo (USP). She was a researcher at Lavid - Laboratory of Applications in Digital Video at Universidade Federal da Paraíba (UFPB). She worked at Unesp's Distance Education Center (Virtual University of the State of São Paulo) and Univesp TV, a digital land channel of TV Cultura's multiprogramming. In 2014, she went to Sapienza Università di Roma for research (funded by Fapesp), as part of her doctoral studies. Currently she works at EAD (Empresa Administradora da Digitalização da TV), the entity responsible for the analog signal switch off and its operations. She has been studying digital TV, interactivity, collaboration, tele-journalism in the digital age, digital convergence, education, and digital inclusion for the past 12 years.

Received in 2017-08-01 | Approved in 2017-11-05 